\title{
THE AGE OF ONSET OF SCHIZOPHRENIA SPECTRUM DISORDERS
}

Jouko Miettunen, Johanna Immonen, John J. McGrath, Matti Isohanni \& Erika Jääskeläinen

Jouko Miettunen, Center for Life Course Health Research, University of Oulu, PO Box 5000, 90014 Oulu, Finland and Medical Research Center Oulu, Oulu University Hospital and University of Oulu, P.O. Box 5000, FIN-90014 Oulu, Finland; email: jouko.miettunen@oulu.fi, phone: +358406742959

Johanna Immonen, Center for Life Course Health Research, University of Oulu, PO Box 5000, 90014 Oulu, Finland and Medical Research Center Oulu, Oulu University Hospital and University of Oulu, P.O. Box 5000, FIN-90014 Oulu, Finland; email: johanna.immonen@student.oulu.fi, phone: +358407174637

John J. McGrath, Queensland Centre for Mental Health Research, a Queensland Brain Institute, University of Queensland, St Lucia, QLD 4072, Australia, and National Centre for Register-based Research, Aarhus BSS, Aarhus University, Aarhus, Denmark; email: j.mcgrath@uq.edu.au, phone: +6173346 6372

Matti Isohanni, Center for Life Course Health Research, University of Oulu, PO Box 5000, 90014 Oulu, Finland email: matti.isohanni@oulu.fi, phone: +358400890024

Erika Jääskeläinen, Center for Life Course Health Research, University of Oulu, PO Box 5000, 90014 Oulu, Finland, Medical Research Center Oulu, Oulu University Hospital and University of Oulu, P.O. Box 5000, FIN-90014 Oulu, Finland Department of Psychiatry, Research Unit of Clinical Neuroscience, University of Oulu, P.O. Box 5000, FIN-90014 Oulu, Finland, and Department of Psychiatry, Oulu University Hospital, P.O. Box 26, FIN-90029 Oulu, Finland; email: erika.jaaskelainen@oulu.fi, phone: +358407474376 


\begin{abstract}
This chapter characterizes the age of onset (AOO) of schizophrenia spectrum disorders and summarizes findings regarding a range of clinical and social outcomes, cognition, brain structure, and mortality. The peak AOO for schizophrenia spectrum disorders is between 20 to 29 years, in where the incidence estimate was among males 4.15 and among females 1.71 per 10,000 person-years. Male gender has been linked with earlier onset age, although among those with family history and cannabis use corresponding gender difference do not exist. Early onset schizophrenia has been linked e.g. with higher familial risk, poor premorbid social adjustment and cannabis use. In adult samples, earlier AOO associated with worse outcome, regarding hospitalisations, negative symptoms, relapses, social and occupational functioning, and global outcome. Also in childhood and adolescence schizophrenia samples, earlier onset has been linked with more severe outcome. Early AOO has been linked also with larger cognitive deficits and brain changes. In the few existing studies, later AOO has been linked with a higher suicide rate. In all, the current study found various differences between patients with different AOO. However, the studies on AOO are relative heterogeneous on methodology and have given varying results. More good quality studies are needed including patients without restriction due to the onset age. AOO is an important characteristic of schizophrenia that could help when examining the origin, genetic mechanism and care of schizophrenia. Understanding factors that influence AOO in schizophrenia may offer clues to prevent or delay the onset of this debilitating group of disorders.
\end{abstract}

KEYWORDS (5 to 10): Schizophrenia, Psychosis, Onset age, Risk factors, Outcome, Cognition, Brain, Suicide 


\subsection{INTRODUCTION}

Schizophrenia spectrum disorders are a complex, often chronic and severe psychiatric disorders and they are one of the leading causes of disability worldwide (WHO 2008). It usually starts early and may cause marked life-long impairments in social, occupational and cognitive functioning, increased mortality and somatic comorbidity, as well as stigma. Schizophrenia spectrum disorders have age of onset (AOO) often in early adulthood (Häfner et al. 1993; Thorup et al. 2007), but it can occur also at childhood or adolescence (Hollis and Rapoport 2011) or even in late adulthood and old age (Howard et al. 2000; Howard and Jeste 2011).

AOO been considered the single most important characteristic of schizophrenia that could help when examining the origin and genetic mechanism of schizophrenia (DeLisi 1992; Goldberg et al. 2011). Onset age is also a crucial determinant of an affected individual's future and socioeconomic costs of the illness to society (Stepniak et al. 2014). For example, schizophrenia is an important contributor to the burden of disease (Whiteford et al. 2013) this not only reflects the disability associated with this disorder, and the suboptimal recovery proportions (13.5\% in meta-analysis by Jääskeläinen et al. 2013), but also the high prevalence of relatively early AOO cases. Understanding the onset distribution of long lasting psychotic disorders can be used in planning preventive and early intervention services (Jones 2013).

The studies on AOO in schizophrenia spectrum disorders, mainly done in schizophrenia, have given variable results, one reason is likely to be the variability in the study designs and in the definition of AOO. Regarding schizophrenia, it is reasonable to assume that most patients receive treatment and thereby their onset age can be estimated at least retrospectively (Jones 2013). Due to this, some studies have defined AOO from the start of positive or other psychotic symptoms, some from first treatment contact, or some from the first hospitalization (Eranti et al. 2013). AOO have been dichotomized in many studies, but it can be studied also with a continuous variable. Often e.g. only early onset schizophrenia (EOS, e.g. onset age below 18 years) or late onset schizophrenia (LOS, e.g. onset age after 40 or 55 years) cases have been studied. Also other terms and definitions are commonly used, such as very early or very late onset schizophrenia. Onset age is thought to be a useful phenotype marker and studies have attempted to found the best cut-offs for 
AOO to differentiate patient groups with varying results. Regarding symptomatology, both EOS (Armando et al. 2015) and LOS (Howard and Jeste 2011) patients have been characterised to have more auditory hallucinations than patients with "regular" age of onset. EOS is characterised also by higher levels negative symptoms and bizarre behaviour (Armando et al. 2015), whereas LOS is characterized to have more delusions (Howard and Jeste 2011).

Previous general systematic reviews focus on either on EOS (Nicolson and Rapoport 1999, Hollis and Rapoport 2011) or LOS (Howard et al. 2000; Howard and Jeste 2011) cases. The systematic review of cognition and onset age included both EOS and LOS cases (Rajji et al. 2009), whereas other specific reviews have studied only EOS or LOS cases. Also different predictors for earlier onset age have been studied (Verdoux et al. 1997; Esterberg et al. 2010; Large et al. 2011; Eranti et al. 2013). In previous studies, earlier AOO of schizophrenia has been found to associate with poorer outcome of illness both in adults (Immonen et al. 2017) and in EOS (Clemmensen et al. 2012). However, most factors related to AOO in schizophrenia have not been studied systematically.

More recently, attention has also been focused on isolated psychotic-like symptoms such as hallucinations and delusions (i.e. psychotic experiences; PEs) (Kelleher et al. 2012; McGrath et al. 2016; McGrath et al. 2017). While most people with these experiences do not develop the full clinical disorder, it is informative to compare the AOO of PEs with the AOO of the full clinical disorder.

The aim of this chapter is to characterize the AOO of schizophrenia spectrum disorders, factors associated with early onset, and how AOO associates with clinical and social outcome, cognition, brain structure, and mortality.

\subsection{INCIDENCE BY AGE AND SEX}

The review by van der Werf et al. (2014) presents incidence rates by gender for different age bands, male had higher risk until the age of 40 years and after that females were at higher risk. In both genders the highest risk was in age group 20 to 29 years, in where the incidence estimate was among males 4.15 and among females 1.71 per 10,000 person-years. Males have earlier onset when compared to females, however the difference is not as large as previously thought. The large register based Danish study (Thorup et al. 2007) found that 
the difference between males and females in median onset age ( 27 vs. 29 years) in ICD schizophrenia was not as large as in mean onset age (29 vs. 33 years), indicating different AOO distribution in the two sexes. The incidence rates by age and sex from their study are presented in the Figure 5.1 (reprinted from Thorup et al. 2007). Of the other schizophrenia spectrum disorders, delusional disorder (Peralta and Cuesta 2016) and schizoaffective disorder (Cotton et al. 2013) have typically later AOO than schizophrenia.

\section{Figure 4.1}

A recent meta-analysis estimated the difference in mean onset age between men and women to be about one year, sex difference was found only in studies using DSM criteria, not in studies based on broader ICD criteria (Eranti et al. 2013). The small gender difference in onset age seems to be present also in other non-affective psychoses (Eranti et al. 2013). Interestingly, the gender differences in AOO do not seem to exist among those with a family history of psychosis (Esterberg et al. 2010), with advanced paternal age (Rosenfield et al. 2010), or using cannabis (Donoghue et al. 2014). Early studies have suggested a second peak in onset age among females (Häfner et al. 1993; Castle et al. 1995), however the review by van der Werf et al. (2014) was not able to detect such a peak. AOO of schizophrenia could be earlier nowadays when compared to previous studies, as Di Maggio et al. (2001) found this in their medical record review of three different birth cohorts.

Community-based surveys have identified that a substantial proportion of individuals who do not have a confirmed psychotic disorder endorse items related to the presence of hallucinations and delusions (psychotic experiences; PEs). Based on 31261 adult (aged 18 and older) across 18 countries, the mean lifetime prevalence of ever having a lifetime PE was 5.8\%, with hallucinatory experiences $(5.2 \%)$ being more common than delusional experiences (1.3\%) (McGrath et al. 2015). With respect to the AOO of PEs, age range. The median (interquartile range) AOO based on projected lifetime estimates was 26 (17-41) years, indicating that PEs commence across a wider age range compared to schizophrenia. In addition, in contrast to schizophrenia, the AOO distributions for PEs did not differ by sex. Curiously, community members who only reported delusional symptoms had a significantly later AOO compared to those who only reported hallucination (McGrath et al. 2016). It can be also noted that early onset of symptoms predicts conversion to psychosis among ultra-high risk individuals (Amminger et al. 2006). 


\subsection{RISK FACTORS FOR EARLY ONSET}

\subsubsection{Genetic influence and family history}

Genetic data and family history have been studied frequently in relation to the onset age of schizophrenia spectrum disorders. Esterberg et al. (2010) performed a meta-analysis on family history of 15 studies. They found that those with a family history of psychosis have significantly younger onset age, with a small effect size (Cohen's $d=0.17$ ). In the individual studies the highest effect sizes were up to 0.54 , but in some studies there was no significant effect and in some of these the effect was even the opposite. Likewise high familial loading has been linked with earlier AOO (Suvisaari et al. 1998, Goldberg et al. 2011).

The studies looking genetic influence have not found any clear evidence. For instance, Stepniak et al. (2014) did not find any direct or indirect effect of polygenic risk score on onset age. On the other hand, Nicolson and Rapoport (1999) reported that childhood-onset cases (onset below age 12) had more severe premorbid neurodevelopmental abnormalities and a seemingly higher rate of familial schizophrenia and spectrum disorders than later onset cases.

\subsubsection{Early risk factors}

Various pregnancy and birth related factors have been studied in association with AOO. Subjects with onset of schizophrenia before age 22 were 2.7 times more likely than those with onset at a later age to have had a history of an abnormal presentation at birth and 10 times more likely to have had a history of complicated Cesarean birth in a meta-analysis of 11 studies (Verdoux et al. 1997). Also studies published after this meta-analysis have found similar association (Castle et al. 1997; Scherr et al. 2012; Stepniak et al. 2014). In the study by Kirov et al. (1996) obstetric complications associated with earlier onset in males, but not in females. Preeclampsia, enuresis/encopresis, and the use of forceps and the need for incubator at birth have been found to associate with early AOO in a sample including all psychoses (Rubio-Abadal et al. 2015). There also seem to be an association between advanced paternal age and earlier onset age (Stepniak et al. 2014). Early (<25 years) onset schizophrenia patients had been found to have higher rate of developmental delays when compared to late (>60 years) onset patients $(11.9 \%$ vs $0 \%$; relative risk $0.88 ; 95 \%$ confidence interval 0.83-0.94) (Castle et al. 1997). 


\subsubsection{Premorbid factors}

Cannabis use and poor premorbid adjustment have been found to associate with early AOO. Regarding cannabis use, a meta-analysis of 41 studies found that the age at onset of psychosis for cannabis users was in average 2.7 years younger than for nonusers (Large et al. 2011). This has been found also in later studies (Scherr et al. 2012; Donoghue et al. 2014). Stepniak et al. (2014) found that cannabis users had not only an earlier mean onset age of schizophrenia (23.2 vs. 25.3 years) but also an earlier onset of prodromal phase (20.2 vs. 22.4 years). It has been also found that earlier onset age among cannabis users may be true especially among females (Compton et al. 2009). The meta-analysis by Large et al. (2011) found earlier onset age also among other substance users. Gunnell et al. (2002) has found lower premorbid IQ to be linked with earlier onset age in a large Swedish conscripts study. Regarding premorbid adjustment, several studies have found poorer premorbid adjustment among early onset cases than late onset cases (Foerster et al. 1991; Gupta et al. 1995; Vourdas et al. 2003; Goldberg et al. 2011).

Interestingly, the amount of environmental factors can associate with early AOO, as the earlier mean onset age of schizophrenia among those with four or more environmental risk factors when compared to those without environmental risk factors (22.6 vs. 30.7 years) and of prodromal phase (19.4 vs. 28.4 years) (Stepniak et al. 2014). However, many studied single risk factors did not associate with AOO (Stepniak et al. 2014). The study by Scherr et al. (2012) looked several predictors for AOO and noted that the factors like obstetric complications and cannabis use are true in non-familial but not in familial schizophrenia.

To summarize, there have been various identified risk factors for earlier onset in schizophrenia spectrum disorders, the statistically significant findings have been summarised in Table 5.1. There are not many studies looking for factors relating especially to LOS, but at least sensory deficits and premorbid personality characteristics have been found to associate with the onset of schizophrenia at a later age (Howard et al. 2011). Late onset patients are also more often married than those with earlier AOO (Vahia et al. 2010).

\section{Table 4.1}

\subsection{AGE OF ONSET AND OUTCOME}


Age at onset is one of the most commonly analysed predictors of the outcome in schizophrenia spectrum disorders but the results obtained in different original studies are far from conclusive. To overcome this issue, there have been systematic reviews on the effect of AOO on the long-term outcome of schizophrenia. Yet, there are no meta-analyses or systematic reviews which have simultaneously analysed the outcomes of all schizophrenia cases, as childhood onset- and late onset schizophrenia tend to be studied independently.

The recent meta-analysis from our group (Immonen et al. 2017) studied onset age and long-term (at least 2-year follow-up) outcome among schizophrenia patients. The results of the study concern mainly adult and adolescent onset schizophrenia even though no upper or lower age limits were applied as such. This is because psychiatric research and treatment tend to be done in either adult, adolescent or children settings and hence, the samples of many studies typically include only these certain patients. Original studies were excluded from the meta-analysis if the sample was biased based on the AOO (i.e., it included only early or late onset patients) as comparability of the effect sizes was required.

Outcomes included clinical outcomes (remission, relapse, hospitalization, positive symptoms, negative symptoms, total symptoms, and general clinical outcome), social/occupational capacity, employment status, and global outcome. There was a statistically significant correlation between younger age at onset and more hospitalizations, more negative symptoms, more relapses, poorer social/occupational functioning, and poorer global outcome. Other relationships were not significant. The effect of age at onset on the outcomes was small as significant correlations ranged from 0.11 to 0.17 . Figure 5.2 shows correlations between age at onset and the included outcome categories (reprinted from Immonen et al. 2017). Positive correlation indicates that an earlier AOO results in poorer outcome. Male gender had a confounding effect on the clinical outcome, as in the samples with a higher proportion of males, the correlation between earlier age at onset and poorer general clinical outcome became significant (Immonen et al. 2017). The effect of age at onset is mostly independent of gender, but it is possible that males with an early onset have a poorer clinical outcome.

\section{Figure 4.2}

Clemmensen et al. (2012) summarise studies on the long-term outcome on early-onset schizophrenia (EOS) and samples including also individuals with later AOO (MIX). The 
sample mean age was restricted to be below 18 years in the included studies. They found out that EOS samples had worse outcomes than MIX samples. The outcome was defined as good, moderate or poor based on the Global Functioning Score or a study specific outcome. Only $15.4 \%$ of the EOS patients had a good outcome compared with $19.6 \%$ of the MIX samples. A poor outcome was experienced by $60.1 \%$ in EOS studies versus $46.8 \%$ in MIX studies. This shows that early manifestation of schizophrenia is connected with a particularly poor prognosis.

Duration of untreated psychosis (DUP) may vary by onset age with late onset patients having shorter DUP (Sato et al. 2004). This indicates that the effect of AOO on the outcome may be even larger as longer DUP has been linked with a worse outcome (Penttilä et al. 2014). However, AAO did not affect the relation of DUP and outcome in the recent meta-analysis (Penttilä et al. 2014). Regarding especially the occupational outcome, it is clear that earlier onset age affects education. For example, in one study those with onset age before 22 years had 6-fold odds for stagnating at the basic educational level, contrasted to cases having onset between 22 and 31 years (Isohanni et al. 2001).

\subsection{AGE OF ONSET AND COGNITION}

Cognitive deficits occur in about $80 \%$ of schizophrenia patients (Palmer et al. 2009). Cognitive dysfunctions rather than positive symptoms are considered to be core features of schizophrenia, since they are strongly correlated with poor functional outcomes, as well as being predictors of general outcome and rehabilitation effectiveness (Keefe et al. 2011).

When compared to adult onset schizophrenia, there is considerable less studies on cognition in early onset and late onset schizophrenia (Rajji et al. 2009). The meta-analysis by Rajji et al. (2009) included studies on onset age and cognition in schizophrenia published between 1980 and 2008. They found that individuals with youth-onset schizophrenia demonstrate larger deficits than those with first-episode schizophrenia in several areas of cognition (arithmetic, executive function, IQ, psychomotor speed of processing and verbal memory). In contrast, those with late-onset schizophrenia demonstrate larger deficits only on attention, fluency, global cognition, IQ and visuospatial construction. They conclude that the cognitive pattern of people with late-onset schizophrenia suggests that their deficits are specific rather than solely as a result of ageing and related factors. It may be good to realise, that at the time of measuring the cognition, the duration of illness was considerably longer 
among studies on late onset schizophrenia (weighted mean 7.7 years), and somewhat longer in youth onset schizophrenia (mean 2.3 years) than first-episode schizophrenia (7.7 years). On the other hand, most marked cognitive decline happen around psychosis, few years before and after the onset and remains relatively stable thereafter (Vyas et al. 2011; Bora and Murray 2014). A review on intelligence scores, reported that scores in EOS often range between 80 and 90, which are lower than those of adult-onset patients (Vyas et al. 2011).

Based on meta-analysis, cognition does not deteriorate after psychosis onset in first episode psychosis or in ultra-high risk samples based on follow-up studies, but instead, there are improvements in cognitive abilities in both groups and this may be due to practice effects and improvement on symptoms (Bora and Murray 2014). There is no evidence of the loss of acquired cognitive skills after the onset of psychosis. Change of verbal learning and memory was analysed in a population based schizophrenia sample around early middleage. Compared to non-psychotic controls, there was no evidence of greater decline in verbal episodic memory between ages 34 and 43 years in schizophrenia though the schizophrenia sample had an overall lower cognitive performance at the baseline (Rannikko et al. 2015).

Cognitive deficits observed in schizophrenia seem to develop long before the onset of psychosis, they seem as consequence of an abnormal neurodevelopment, and they may be best explained by problems in acquisition on certain skills during neurodevelopment. This would explain the association between earlier onset age and poorer functioning in some cognitive tasks.

\subsection{AGE OF ONSET AND BRAIN MRI}

AOO has been linked also with brain alterations. Fraguas et al. (2016) have reviewed studies on progression of brain changes in early onset psychosis when compared to controls. Early onset patients showed greater progressive frontal grey matter loss over the first few years after illness onset, age at baseline MRI was associated with greater loss of temporal grey matter volume over time in patients compared with controls (Fraguas et al. 2016).

The studies including adult samples have also looked effect of AOO on brain volumes (for review, see Hahn et al. 2014). The previous studies have found earlier onset age to associate e.g. with lower volumes in thalamus (Corey-Bloom et al. 1995) and temporal lobe (DeLisi and Hoff 2005), and larger ventricular volumes (DeLisi et al. 1995; DeLisi et al. 
2004; Tonkonogy and Geller 1999). Table 5.2 summaries statistically significant findings on AOO and brain morphometry in schizophrenia. There are only a few Diffusion Tensor Imaging (DTI) or functional neuroimaging studies with mixed results (Hahn et al. 2014). In one DTI study, a differential effect of age at onset was noted bilaterally in medial prefrontal white matter $(\mathrm{P}=0.002)$, these regions included parts of the superior fronto-occipital fasciculus, corticopontine tract, anterior thalamic radiation, and corpus callosum (Kyriakopoulos et al. 2009)

\section{Table 4.2}

\subsection{AGE OF ONSET AND MORTALITY}

In their comprehensive review on risk factors for suicide in schizophrenia, Popovic et al. (2014) found that among schizophrenia patients, older AOO associated with suicide, however this was based only on two studies. On the other hand, Panariello et al. (2010) have reported that EOS cases (AOO below 22 years) had more suicidal attempts (30\% vs. 20\%) than LOS cases (AOO above 22 years). A meta-analysis looking factors associated with either suicide attempts or deliberate self-injury, found that these were predicted by for instance younger age of onset and younger age at first treatment (Challis et al. 2013).

Regarding mortality due to natural causes there are not many studies looking AOO. In a Dutch study among older patients, mortality compared to general population was still high, but AOO did not associate with higher mortality risk (Meesters et al. 2016). In a Finnish register study among older patients, AOO after 60 years, especially among males, associated with a higher risk of death than those with an earlier AOO. This finding was mostly explained with physical comorbidities and accidents (Talaslahti et al. 2015).

Regarding reasons for high mortality due to natural causes, somatic comorbidities are common in schizophrenia. EOS cases may have in adulthood and in old age a higher somatic burden e.g. due to higher cumulative antipsychotic use and smoking. Studies on the topic are quite rare, a study in the Northern Finland Birth Cohort 1966 indicates that EOS cases could be at higher risk for insulin resistance (Timonen et al. 2009). On the other hand, LOS cases (onset after age 40 years) are at two to three times higher risk of subsequently getting a diagnosis of dementia compared to patients with osteoarthritis and compared to the general population (Kørner et al. 2009). 


\subsection{DISCUSSION}

We have reviewed research on $\mathrm{AOO}$ in schizophrenia regarding clinical and social outcomes, cognition, brain structure, and mortality. Summary of the findings of the study is presented in the Box 5.1.

The findings are consistent with the view that earlier onset of schizophrenia associates with poor outcome. Adolescence includes rapid brain development but also unique and critical psychosocial alterations: a separation from original family and independence, education, occupational decisions, start of dyadic and family relations. Early onset schizophrenia may prevent these critical developmental steps, e.g. stop educational path (Isohanni et al. 2001). The missing achievement of adulthood identity may also jeopardize coping with the disease and collaboration with treatment systems. It has been shown that both brain changes (Rossi et al. 2000; Mitelman et al. 2007; Jääskeläinen et al. 2014) and poor premorbid social adjustments (Alvarez-Jimenez et al. 2012) associate with poor outcome. It has also been found that $\mathrm{AOO}$ and premorbid functioning may act as mediators between gender, familial history of psychosis and clinical outcome (Goldberg et al. 2011). Thus, AOO may determine the degree to which brain structural change and cognitive impairments lead to a poor outcome.

Treatment adherence can be poor especially in EOS cases, for instance schizophrenia individuals having AAO under 23 year participated less often to psychosocial therapies in therapeutic community ward (Isohanni and Nieminen 1990). Response to the treatment in the first episode has also been reported being poorer among those with earlier AOO. In one study, after a 10-year follow-up $84 \%$ of treatment resistant psychosis cases were treatment resistant from illness onset, and younger age at onset and longer DUP predicted treatment resistance from illness onset (Demjaha et al. 2015). The EOS are likely to have larger cumulative exposure to antipsychotic medication if they survive to old age, this may relate to a poorer long-term outcome relating to cognition (Husa et al. 2017), brain changes (Huhtaniska et al. 2017), and somatic outcomes e.g. due to weight gain and insulin resistance (Newcomer and Leucht 2011).

Because of the poor outcome there are several different types of interventions targeted to these patients (Bertolote and McGorry 2005; Jones 2013). Family interventions, for instance, have been suggested as early psychosis can have a negative impact on service 
users and their families (Onwumere et al. 2011). The early interventions are potentially useful, as young people with psychosis have for instance smaller social networks when compared to their peers (Macdonald et al. 2000). According to the recent review cognitive behavioural therapy, cognitive remediation, and family intervention have shown some good results also in EOS patients (Armando et al. 2015). Alverez-Jimenez et al. (2011) suggest that benign and cost-effective treatment approaches including adequate social and family support are optimal for young first onset patients which minimize the side effects of prolonged exposure to antipsychotic medication. The results of this review indicate that if we can delay AOO for schizophrenia this could reduce the burden of the disease. Maybe prevention if not achievable, but delay would be a good surrogate outcome.

Schizophrenia starts usually in adolescence and early adulthood. The diagnostic criteria for schizophrenia are the same regardless onset age, but there has been discussion if there should be subtypes based on AOO (Tonkonogy and Geller 1999). Also regarding current at-risk and psychotic-onset criteria there has been discussion about their validity especially in children compered to adults (Armando et al. 2015). The onset age has been defined and categorised differently in the included studies and samples have been selected partly based on AOO, this may have effects regarding these findings. Also in general, the results on $\mathrm{AOO}$ of schizophrenia studies may be biased as studies often include patients in different phases of illness. A first episode study would be preferable, as those with EOS surviving to old age are also likely to have better outcome regarding all aspects of illness than those deceased. Due to gender differences in onset age, this mean that more males are included if these cases are excluded. Many studies also exclude those with late AOO due to study methodology, due to this the studies may include less female patients than otherwise would be the case (van der Werf et al. 2014). Regarding gender differences, those were not present among patients with various risk factors (cannabis use, family history, and advanced paternal age), perhaps indicating that these factors have potential to override the sex differences in AOO.

\subsection{CONCLUSIONS}

AOO is an important characteristic of schizophrenia that could help when examining the origin, genetic mechanism and care of schizophrenia. The current review found a lot of research on various topics relating to AOO in schizophrenia, but more good quality studies 
are needed that include patients, without restriction due to the onset age. Understanding factors that influence AOO in schizophrenia may offer clues to prevent or at least delay the onset of this debilitating group of disorders. 
Acknowledgments

This work was supported by grants from the NARSAD: Brain and Behavior Research Fund and the Academy of Finland (\#268 336, \#278 286). The funders had no role in the manuscript. 


\section{References}

Alvarez-Jimenez M, Gleeson JF, Henry LP, Harrigan SM, Harris MG, Amminger GP, Killackey E, Yung AR, Herrman H, Jackson HJ, McGorry PD. Prediction of a single psychotic episode: a 7.5-year, prospective study in first-episode psychosis. Schizophr Res. 2011;125:236-46.

Alvarez-Jimenez M, Priede A, Hetrick SE, Bendall S, Killackey E, Parker AG, McGorry PD, Gleeson JF. Risk factors for relapse following treatment for first episode psychosis: a systematic review and meta-analysis of longitudinal studies. Schizophr Res. 2012;139:11628.

Amminger GP, Leicester S, Yung AR, Phillips LJ, Berger GE, Francey SM, Yuen HP, McGorry PD. Early onset of symptoms predicts conversion to non-affective psychosis in ultra-high risk individuals. Schizophr Res. 2006;84:67-76.

Bellino S, Rocca P, Patria L, Marchiaro L, Rasetti R, Di Lorenzo R, Paradiso E, Bogetto F. Relationships of age at onset with clinical features and cognitive functions in a sample of schizophrenia patients. J Clin Psychiatry 2004;65:908-14.

Bertolote J, McGorry P (2005). Early intervention and recovery for young people with early psychosis: consensus statement. Br J Psychiatry 2005;48 Suppl:116-9.

Bora E, Murray RM. Meta-analysis of cognitive deficits in ultra-high risk to psychosis and first-episode psychosis: do the cognitive deficits progress over, or after, the onset of psychosis? Schizophr Bull. 2014;40:744-55.

Byrne M, Agerbo E, Mortensen PB. Family history of psychiatric disorders and age at first contact in schizophrenia: an epidemiological study. Br J Psychiatry 2002;43 Suppl:19-25.

Castle DJ, Abel K, Takei N, Murray RM. Gender differences in schizophrenia: hormonal effect or subtypes? Schizophr Bull. 1995;21:1-12.

Castle DJ, Wessely S, Howard R, Murray RM. Schizophrenia with onset at the extremes of adult life. Int J Geriatr Psychiatry 1997;12:712-7.

Challis S, Nielssen O, Harris A, Large M. Systematic meta-analysis of the risk factors for deliberate self-harm before and after treatment for first-episode psychosis. Acta Psychiatr Scand. 2013;127:442-54. 
Clemmensen L, Vernal DL, Steinhausen HC. A systematic review of the long-term outcome of early onset schizophrenia. BMC Psychiatry 2012;12:150.

Compton MT, Kelley ME, Ramsay CE, Pringle M, Goulding SM, Esterberg ML, Stewart T, Walker EF. Association of pre-onset cannabis, alcohol, and tobacco use with age at onset of prodrome and age at onset of psychosis in first-episode patients. Am J Psychiatry 2009;166:1251-7.

Corey-Bloom J, Jernigan T, Archibald S, Harris MJ, Jeste DV. Quantitative magnetic resonance imaging of the brain in late-life schizophrenia. Am J Psychiatry 1995;152:447-9.

Cotton SM, Lambert M, Schimmelmann BG, Mackinnon A, Gleeson JF, Berk M, Hides L, Chanen AM, Scott J, Schöttle D, McGorry PD, Conus P. Differences between first episode schizophrenia and schizoaffective disorder. Schizophr Res. 2013;147:169-74.

DeLisi LE. The significance of age of onset for schizophrenia. Schizophr Bull. 1992;18:209_ 15.

DeLisi LE, Hoff AL. Failure to find progressive temporal lobe volume decreases 10 years subsequent to a first episode of schizophrenia. Psychiatry Res Neuroimaging 2005;138:2658.

DeLisi, LE, Sakuma, M, Maurizio, AM, Relja, M, Hoff, AL. Cerebral ventricular change over the first 10 years after the onset of schizophrenia. Psychiatry Res Neuroimaging 2004;130:57-70.

DeLisi LE, Tew W, Xie S, Hoff AL, Sakuma M, Kushner M, Lee G, Shedlack K, Smith AM, Grimson R. A prospective follow-up study of brain morphology and cognition in firstepisode schizophrenic patients: preliminary findings. Biol Psychiatry 1995;38:349-60.

Demjaha A, Lappin JM, Stahl D, Patel MX, MacCabe JH, Howes OD, Heslin M, Reininghaus UA, Donoghue K, Lomas B, Charalambides M, Onyejiaka A, Fearon P, Jones P, Doody G, Morgan C, Dazzan P, Murray RM. Antipsychotic treatment resistance in first-episode psychosis: prevalence, subtypes and predictors. Psychol Med. 2017.

Díaz-Caneja CM, Pina-Camacho L, Rodríguez-Quiroga A, Fraguas D, Parellada M, Arango C. Predictors of outcome in early-onset psychosis: a systematic review. NPJ Schizophr. 2015; 1:14005. doi:10.1038/npjschz.2014.5. 
Di Maggio C, Martinez M, Ménard JF, Petit M, Thibaut F. Evidence of a cohort effect for age at onset of schizophrenia. Am J Psychiatry 2001;158:489-92.

Donoghue K, Doody GA, Murray RM, Jones PB, Morgan C, Dazzan P, Hart J, Mazzoncini $\mathrm{R}$, Maccabe JH. Cannabis use, gender and age of onset of schizophrenia: data from the ÆESOP study. Psychiatry Res. 2014;215:528-32..

Eranti SV, MacCabe JH, Bundy H, Murray RM. Gender difference in age at onset of schizophrenia: a meta-analysis. Psychol Med. 2013;43:155-67..

Esterberg ML, Trotman HD, Holtzman C, Compton MT, Walker EF. The impact of a family history of psychosis on age-at-onset and positive and negative symptoms of schizophrenia: a meta-analysis. Schizophr Res. 2010;120:121-30.

Foerster A, Lewis SW, Owen MJ, Murray RM. Low birth weight and a family history of schizophrenia predict poor premorbid functioning in psychosis. Schizophr Res. 1991;5:1320.

Fraguas D, Díaz-Caneja CM, Pina-Camacho L, Janssen J, Arango C. Progressive brain changes in children and adolescents with early-onset psychosis: A meta-analysis of longitudinal MRI studies. Schizophr Res. 2016;173:132-9.

Goldberg X, Fatjó-Vilas M, Penadés R, Miret S, Muñoz MJ, Vossen H, Fañanás L. Neurodevelopmental liability to schizophrenia: the complex mediating role of age at onset and premorbid adjustment. Schizophr Res. 2011;133:143-9.

Gourion D, Goldberger C, Leroy S, Bourdel MC, Olié JP, Krebs MO. Age at onset of schizophrenia: interaction between brain-derived neurotrophic factor and dopamine D3 receptor gene variants. Neuroreport 2005;16:1407-10.

Gunnell D, Harrison G, Rasmussen F, Fouskakis D, Tynelius P. Associations between premorbid intellectual performance, early-life exposures and early-onset schizophrenia. Cohort study. Br J Psychiatry 2002;181:298-305.

Gupta S, Rajaprabhakaran R, Arndt S, Flaum M, Andreasen NC. Premorbid adjustment as a predictor of phenomenological and neurobiological indices in schizophrenia. Schizophr Res. 1995;16:189-97. 
Häfner H, Maurer K, Löffler W, Riecher-Rössler A. The influence of age and sex on the onset and early course of schizophrenia. Br J Psychiatry 1993;162:80-6.

Hahn C, Lim HK, Lee CU. Neuroimaging findings in late-onset schizophrenia and bipolar disorder. J Geriatr Psychiatry Neurol. 2014;27:56-62.

Hollis C, Rapoport J. Child and adolescent schizophrenia. In Weinberger DR, Harrison PJ, editors. Schizophrenia, 3rd edition. Chichester: Blackwell Publishing Ltd., 2011. p. 24-46.

Howard R, Jeste DV. Late-onset schizophrenia. In Weinberger DR, Harrison PJ, editors. Schizophrenia, 3rd edition. Chichester: Blackwell Publishing Ltd., 2011. p. 47-61.

Howard, R, Rabins, PV, Seeman, MV, Jeste, DV (2000). Late-onset schizophrenia and verylate-onset schizophrenia-like psychosis: An international consensus. The International LateOnset Schizophrenia group. Am J Psychiatry 2000;157:172-8.

Huhtaniska H, Jääskeläinen E, Hirvonen N, Remes J, Murray GK, Veijola J, Isohanni M, Miettunen J. Long-term antipsychotic use and brain changes in schizophrenia - a systematic review and meta-analysis. Hum Psychopharmacol. 2017; 32:2. doi:10.1002/hup.2574.

Husa A, Moilanen J, Murray G, Marttila R, Haapea M, Rannikko I, Barnett JH, Jones P, Isohanni M, Remes AM, Koponen H, Miettunen J, Jääskeläinen E. Lifetime antipsychotic medication and cognitive performance in schizophrenia at age 43 years in a general population birth cohort. Psychiatry Res. 2017;247:130-8.

Immonen J, Jääskeläinen E, Korpela H, Miettunen J. Age at onset and the outcomes of schizophrenia: systematic review and meta-analysis. Early Interv Psychiatry 2017;11:45360.

Isohanni I, Jones PB, Järvelin M-R, Nieminen P, Rantakallio P, Jokelainen J, Croudace TJ, Isohanni M. Educational consequences of mental disorders treated in hospital. A 31-year follow-up of the Northern Finland 1966 Birth Cohort. Psychol Med. 2001;31:339-49.

Isohanni M, Nieminen P. The determinants of therapeutic community activity at an acute patients' psychiatric ward. Int J Ther Communities 1990;11:139 48.

Jääskeläinen E, Juola P, Hirvonen N, McGrath JJ, Saha S, Isohanni M, Veijola J, Miettunen J. A systematic review and meta-analysis of recovery in schizophrenia. Schizophr Bull. 2013;39:1296-306. 
Jääskeläinen E, Juola P, Kurtti J, Haapea M, Kyllönen M, Miettunen J, Tanskanen P, Murray G.K, Huhtaniska S, Barnes A, Vei-jola J, Isohanni M. Associations between brain morphology and outcome in schizophrenia in a general population sample. Eur Psychiatry 2014;29:456-62.

Jeste DV, McAdams L A, Palmer BW, Braff D, Jernigan TL, Paulsen JS, Stout JC, Symonds LL, Bailey A, Heaton RK. Relationship of neuropsychological and MRI measures to age of onset of schizophrenia. Acta Psychiatr Scand. 1998;98:156-64.

Jones PB. Adult mental health disorders and their age at onset. Br J Psychiatry 2013;54 Suppl: 5-10.

Keefe RS, Vinogradov S, Medalia A, Silverstein Sm, Bell MD, Diskinson D, Ventura J, Marder SR, Stroup T. Report from the working group conference on multisite trial design for cognitive remediation in schizophrenia. Schizophr Bull. 2011;37 Suppl 5: 1057-65.

Kelleher I, Keeley H, Corcoran P, Lynch F, Fitzpatrick C, Devlin N, Molloy C, Roddy S, Clarke MC, Harley M, Arseneault L, Wasserman C, Carli V, Sarchiapone M, Hoven C, Wasserman D, Cannon M. Clinicopathological significance of psychotic experiences in nonpsychotic young people: evidence from four population-based studies. Br J Psychiatry 2012;201:26-32.

Kendler KS, MacLean CJ. Estimating familial effects on age at onset and liability to schizophrenia. I. Results of a large sample family study. Genet Epidemiol. 1990;7:409-17.

Kirov G, Jones PB, Harvey I, Lewis SW, Toone BK, Rifkin L, Sham P, Murray RM. Do obstetric complications cause the earlier age at onset in male than female schizophrenics? Schizophr Res. 1996;20:117-24.

Kørner A, Lopez AG, Lauritzen L, Andersen PK, Kessing LV. Late and very-late first-contact schizophrenia and the risk of dementia - a nationwide register based study. Int J Geriatr Psychiatry. 2009;24:61-7.

Kyriakopoulos M, Perez-Iglesias R, Woolley JB, Kanaan RA, Vyas NS, Barker GJ, Frangou S, McGuire PK. Effect of age at onset of schizophrenia on white matter abnormalities. Br J Psychiatry 2009;195:346-53. 
Large M, Sharma S, Compton MT, Slade T, Nielssen O. Cannabis use and earlier onset of psychosis: a systematic meta-analysis. Arch Gen Psychiatry 2011;68:555-61.

Macdonald EM, Hayes RL, Baglioni AJ. The quantity and quality of the social networks of young people with early psychosis compared with closely matched controls. Schizophr Res. 2000;46:25-30.

McGrath JJ, McLaughlin KA, Saha S, Aguilar-Gaxiola S, Al-Hamzawi A, Alonso J, Bruffaerts R, de Girolamo G, de Jonge P, Esan O, Florescu S, Gureje O, Haro JM, Hu C, Karam EG, Kovess-Masfety V, Lee S, Lepine JP, Lim CC, Medina-Mora ME, Mneimneh Z, Pennell BE, Piazza M, Posada-Villa J, Sampson N, Viana MC, Xavier M, Bromet EJ, Kendler KS, Kessler RC. The association between childhood adversities and subsequent first onset of psychotic experiences: a cross-national analysis of 23998 respondents from 17 countries. Psychol Med. 2017;47:1230-45.

McGrath JJ, Saha S, Al-Hamzawi A, Alonso J, Bromet EJ, Bruffaerts R, Caldas-de-Almeida JM, Chiu WT, de Jonge P, Fayyad J, Florescu S, Gureje O, Haro JM, Hu C, Kovess-Masfety V, Lepine JP, Lim CC, Mora ME, Navarro-Mateu F, Ochoa S, Sampson N, Scott K, Viana MC, Kessler RC. Psychotic experiences in the general population: A cross-national analysis based on 31261 respondents from 18 Countries. JAMA Psychiatry 2015;72:697-705.

McGrath JJ, Saha S, Al-Hamzawi AO, Alonso J, Andrade L, Borges G, Bromet EJ, Oakley Browne M, Bruffaerts R, Caldas de Almeida JM, Fayyad J, Florescu S, de Girolamo G, Gureje O, Hu C, de Jonge P, Kovess-Masfety V, Lepine JP, Lim CC, Navarro-Mateu F, Piazza M, Sampson N, Posada-Villa J, Kendler KS, Kessler RC. Age of onset and lifetime projected risk of psychotic experiences: cross-national data from the world mental health survey. Schizophr Bull. 2016;42:933-41.

Meesters PD, Comijs HC, Smit JH, Eikelenboom P, de Haan L, Beekman AT, Stek ML. Mortality and its determinants in late-life schizophrenia: a 5-year prospective study in a Dutch catchment area. Am J Geriatr Psychiatry 2016;24:272-7. doi:

Mitelman SA, Brickman AM, Shihabuddin L, Newmark RE, Hazlett EA, Haznedar MM, Buchsbaum MS. A comprehensive assessment of gray and white matter volumes and their relationship to outcome and severity in schizophrenia. Neuroimage 2007;37:449-62. 
Newcomer JW, Leucht S. Metabolic adverse effects associated with antipsychotic medications. In: Weinberger DR, Harrison PJ, editors. Schizophrenia, 3rd edition.WileyBlackwell; 2011. p.588-97.

Nicolson R, Rapoport JL. Childhood-onset schizophrenia: rare but worth studying. Biol Psychiatry 1999;46:1418-28.

Onwumere J, Bebbington P, Kuipers E. Family interventions in early psychosis: specificity and effectiveness. Epidemiol Psychiatr Sci. 2011;20:113-9.

Palmer BW, Dawes SE, Heaton RK. What do we know about neuropsychological aspects of schizophrenia? Neuropsychol Rev. 2009;19: 365-84.

Panariello F, O'Driscoll L, de Souza RP, Tiwari A, Manchia M, Kennedy J, DeLuca V. Age at onset in Canadian schizophrenia patients: admixture analysis. Schizophr Res. 2010;122:2789.

Penttilä M, Jääskeläinen E, Hirvonen N, Isohanni M, Miettunen J. Duration of untreated psychosis as predictor of long-term outcome in schizophrenia. A systematic review and meta-analysis. Br J Psychiatry 2014;205:88-94.

Peralta V, Cuesta MJ. Delusional disorder and schizophrenia: a comparative study across multiple domains. Psychol Med. 2016;46:2829-39..

Popovic D, Benabarre A, Crespo JM, Goikolea JM, González-Pinto A, Gutiérrez-Rojas L, Montes JM, Vieta E. Risk factors for suicide in schizophrenia: systematic review and clinical recommendations. Acta Psychiatr Scand. 2014;130:418-26.

Rajji TK, Ismail Z, Mulsant BH. Age at onset and cognition in schizophrenia: meta-analysis. Br J Psychiatry 2009;195:286-93.

Rannikko I, Haapea M, Miettunen J, Veijola J, Murray GK, Barnett JH, Husa AP, Jones PB, Isohanni M, Jääskeläinen E. Changes in verbal learning and memory in schizophrenia and non-psychotic controls in midlife: A nine-year follow-up in the Northern Finland Birth Cohort study 1966. Psychiatry Res. 2015;228:671-9.

Rosenfield PJ, Kleinhaus K, Opler M, Perrin M, Learned N, Goetz R, Stanford A, Messinger J, Harkavy-Friedman J, Malaspina D. Later paternal age and sex differences in schizophrenia symptoms. Schizophr Res. 2010;116:191-5. 
Rossi A, Bustini M, Prosperini P, Marinangeli MG, Splendiani A, Daneluzzo E, Stratta P. Neuromorphological abnormalities in schizophrenic patients with good and poor outcome. Acta Psychiatr Scand. 2000;101:161-6.

Rubio-Abadal E, Ochoa S, Barajas A, Baños I, Dolz M, Sanchez B, Del Cacho N, Carlson J, Huerta-Ramos E; GENIPE Group, Usall J. Birth weight and obstetric complications determine age at onset in first episode of psychosis. J Psychiatr Res. 2015;65:108-14.

Sato T, Bottlender R, Schröter A, Möller HJ. Psychopathology of early-onset versus lateonset schizophrenia revisited: an observation of 473 neuroleptic-naive patients before and after first-admission treatments. Schizophr Res. 2004;67:175-83.

Scherr M, Hamann M, Schwerthöffer D, Froböse T, Vukovich R, Pitschel-Walz G, Bäuml J. Environmental risk factors and their impact on the age of onset of schizophrenia: Comparing familial to non-familial schizophrenia. Nord J Psychiatry 2012;66:107-14.

Stepniak B, Papiol S, Hammer C, Ramin A, Everts S, Hennig L, Begemann M, Ehrenreich H. Accumulated environmental risk determining age at schizophrenia onset: a deep phenotyping-based study. Lancet Psychiatry 2014;1:444-53.

Suvisaari JM, Haukka J, Tanskanen A, Lönnqvist JK. Age at onset and outcome in schizophrenia are related to the degree of familial loading. Br J Psychiatry 1998;173:494-500.

Talaslahti T, Alanen HM, Hakko H, Isohanni M, Häkkinen U, Leinonen E. Patients with very-late-onset schizophrenia-like psychosis have higher mortality rates than elderly patients with earlier onset schizophrenia. Int J Geriatr Psychiatry 2015;30:453-9. doi: 10.1002/gps.4159.

Thorup A, Waltoft BL, Pedersen CB, Mortensen PB, Nordentoft M. Young males have a higher risk of developing schizophrenia: a Danish register study. Psychol Med. 2007;37:479_ 84.

Timonen MJ, Saari KM, Jokelainen JJ, Meyer-Rochow VB, Räsänen PK, Koponen HJ. Insulin resistance and schizophrenia: results from the Northern Finland 1966 Birth Cohort. Schizophr Res. 2009;113:107-8.

Tonkonogy JM, Geller JL. Late-onset paranoid psychosis as a distinct clinicopathologic entity: magnetic resonance imaging data in elderly patients with paranoid psychosis of late 
onset and schizophrenia of early onset. Neuropsychiatry Neuropsychol Behav Neurol. $1999 ; 12: 230-5$.

Tuulio-Henriksson A, Partonen T, Suvisaari J, Haukka J, Lönnqvist J. Age at onset and cognitive functioning in schizophrenia. Br J Psychiatry 2004;185:215-9.

Vahia IV, Palmer BW, Depp C, Fellows I, Golshan S, Kraemer HC, Jeste DV. Is late-onset schizophrenia a subtype of schizophrenia? Acta Psychiatr Scand. 2010;122:414-26.

van der Werf M, Hanssen M, Köhler S, Verkaaik M, Verhey FR; RISE Investigators, van Winkel R, van Os J, Allardyce J. Systematic review and collaborative recalculation of 133,693 incident cases of schizophrenia. Psychol Med. 2014;44:9-16.

Verdoux H, Geddes JR, Takei N, Lawrie SM, Bovet P, Eagles JM, Heun R, McCreadie RG, McNeil TF, O'Callaghan E, Stöber G, Willinger MU, Wright P, Murray RM. Obstetric complications and age at onset in schizophrenia: an international collaborative metaanalysis of individual patient data. Am J Psychiatry 1997;154:1220-7.

Vourdas A, Pipe R, Corrigall R, Frangou S. Increased developmental deviance and premorbid dysfunction in early onset schizophrenia. Schizophr Res. 2003;62:13-22.

Vyas NS, Patel NH, Puri BK. Neurobiology and phenotypic expression in early onset schizophrenia. Early Interv Psychiatry 2011;5:3-14.

Whiteford HA, Degenhardt L, Rehm J, Baxter AJ, Ferrari AJ, Erskine HE, Charlson FJ, Norman RE, Flaxman AD, Johns N, Burstein R, Murray CJ, Vos T. Global burden of disease attributable to mental and substance use disorders: findings from the Global Burden of Disease Study 2010. Lancet 2013;382:1575-86.

WHO: The Global Burden of Disease: 2004 Update. World Health Organization Press, Geneva.http://www.who.int/healthinfo/global_burden_disease/

GBD_report_2004update_full.pdf (2008). Assessed 29 Jun 2017. 
Table 4.1 Statistically significant predictors for early onset of schizophrenia found in previous meta-analyses and original studies.

Predictors

\section{FAMILY HISTORY AND GENETIC INFLUENCE}

- Meta-analysis of 15 studies published 2008 or earlier found that those with family history of psychosis have significantly younger onset age, with small effect size (Cohen's d $=0.17)($ Esterberg et al. 2010)

- In a later study, those with parental history of psychosis had earlier onset age (17.4 vs. 20.7 years) and association was significant also for father's history of psychosis (17.4 vs 20.6 years) (Rubio-Abadal et al. 2015)

- $\quad$ Earlier onset of schizophrenia have been associated also with family history of affective disorders and any psychiatric disorder (Kendler and MacLean 1990, Byrne et al. 2002)

- $\quad$ Those with high familial loading had earliest average onset of schizophrenia (23.7 years) when compared to those with intermediate (24.3) and low familial loading (25.8) (Suvisaari et al. 1998). In the study by Goldberg et al. (2011) higher familial loading index correlated with earlier onset age $(r=-0.30)$.

- Combination of met-containing genotypes of BDNF gene and Ser/Ser D3 receptor predicted earlier mean onset age of schizophrenia (18.9 vs. 22.0 years) and of prodromal phase (14.2 vs. 16.3 years) (Gourion et al. 2005)

\section{$\underline{\text { EARLY FACTORS }}$}

- $\quad$ Subjects with onset of schizophrenia before age 22 were 2.7 times more likely than those with onset at a later age to have had a history of abnormal presentation at birth and 10 times more likely to have had a history of complicated Cesarean birth in a meta-analysis of 11 studies published 1996 or earlier (Verdoux et al. 1997)

- In later studies, very early (<25 years) had higher rate of obstetric complications when compared to very late (>60 years) onset patients (14.1 vs $4.5 \%$; relative risk $0.29 ; 95 \%$ confidence interval 0.03-2.29) (Castle et al. 1997). In linear regression, birth complications predicted earlier onset (beta 0.34, $\mathrm{p}=0.001$ ) (Scherr et al. 2012) 
- $\quad$ Earlier mean onset age of schizophrenia (23.7 vs. 25.5 years) and of prodromal phase (20.5 vs. 22.7 years) among those with perinatal complications (Stepniak et al. 2014)

- Lower birth weight associated significantly with earlier onset age $(r=0.30)$, this association remained when other significant predictors were taken into account (RubioAbadal et al. 2015). Sample included all psychoses $(n=90)$, of which 37 had schizophrenia spectrum disorder.

- Very early (<25 years) had higher rate of developmental difficulty when compared to very late (>60 years) onset patients $(11.9 \%$ vs $0 \%$; relative risk $0.88 ; 95 \%$ confidence interval 0.83-0.94) (Castle et al. 1997). In linear regression, developmental delays have been linked with earlier onset of schizophrenia (beta 0.29, p=0.002) (Scherr et al. 2012)

- $\quad$ Those with preeclampsia had earlier mean onset age (15.1 vs. 19.4 years) (RubioAbadal et al. 2015). Sample included all psychoses $(n=90)$, of which 37 had schizophrenia spectrum disorder.

- $\quad$ Use of forceps at birth associated with earlier mean onset of psychosis (15.6 vs. 19.4 years), this association remained when other significant predictors were taken into account (Rubio-Abadal et al. 2015). Sample included all psychoses ( $n=90)$, of which 37 had schizophrenia spectrum disorder.

- $\quad$ Need for incubator at birth associated with earlier mean onset of psychosis (15.3 vs. 19.4 years) (Rubio-Abadal et al. 2015). Sample included all psychoses (n=90), of which 37 had schizophrenia spectrum disorder.

- In linear regression, enuresis/encopresis predicted earlier onset (beta 0.26, $\mathrm{p}=0.006$ ) (Scherr et al. 2012)

\section{$\underline{\text { PREMORBID FACTORS }}$}

- Meta-analysis of 41 studies published 2010 or earlier found that the age at onset of psychosis for cannabis users was in average 2.7 years younger than for nonusers (Large et al. 2011)

- $\quad$ Also in later studies, cannabis users have had an earlier age of first symptom than non-users. The gender difference in age of onset was diminished in cannabis smokers 
compared with non-cannabis smokers (Donoghue et al. 2014). In linear regression, cannabis use has been associated with earlier onset (beta 0.32, p=0.001) (Scherr et al. 2012)

- $\quad$ Earlier mean onset age of schizophrenia (23.2 vs. 25.3 years) and of prodromal phase (20.2 vs. 22.4 years) among those using cannabis (Stepniak et al. 2014)

- Meta-analysis of 41 studies published 2010 or earlier found that the age at onset of psychosis for those using any substances (alcohol, cannabis or other) was in average 2.0 years earlier than for nonusers (Large et al. 2011)

- $\quad$ Stimulant drug use previous to psychosis onset associated with earlier mean onset of psychosis (18.1 vs. 20.7 years) (Rubio-Abadal et al. 2015)

- $\quad$ Earlier mean onset age of schizophrenia was found among those with four or more environmental risk factors when compared to those without environmental risk factors (22.6 vs. 30.7 years) and of prodromal phase (19.4 vs. 28.4 years) (Stepniak et al. 2014)

- $\quad$ Poorer childhood and adolescent premorbid adjustment associated significantly with earlier age of onset $(r=0.36, p=0.0001)($ Gupta et al. 1995)

- $\quad$ Early onset patients showed more deviant premorbid social adjustment and higher scores of Premorbid Schizoid and Schizotypal Traits when compared with late onset patients (Vourdas et al. 2003)

- $\quad$ Earlier mean onset age of schizophrenia (24.3 vs. 26.1 years) and of prodromal phase (21.3 vs. 23.4 years) among those with neurotrauma (Stepniak et al. 2014) 
Table 4.2 Statistically significant associations between onset age of schizophrenia found in original studies.

- $\quad$ Larger thalamic volume in late onset schizophrenia (>45y) when compared with earlier onset $(t=2.90$, degrees of freedom, d.f. $=56, P<0.05)$ (Corey-Bloom et al. 1995)

- $\quad$ Earlier age of onset correlated with larger volumes of caudate $(r=-0.29)$ and lenticular nuclei $(r=0.24)$ (Jeste et al. 1998)

- Younger age at first hospitalization associated with greater reduction in right temporal lobe size over time $(r=0.44, P=0.02)$ (DeLisi and Hoff 2005)

- Younger age at first symptoms associated with decrease in left caudate $(r=0.46$, $\mathrm{P}<0.05)$ in a 4-year follow up (DeLisi et al. 1995)

- Younger age at first hospitalization associated with less reduction in right lateral ventricle size over time $(r=0.45, P=0.02)$ (DeLisi et al. 1995). The rate of ventricular change during the first 5 years was significantly correlated (left ventricle: $r=0.58$; right ventricle: $\mathrm{r}=0.42$ ) with age at first hospitalization (DeLisi et al. 2004).

- $\quad$ More frequent moderate to severe ventricular abnormalities (29\% vs. $0 \%, \mathrm{P}=0.004)$ and cortical atrophy $(23 \%$ vs. $0 \%, \mathrm{P}=0.01)$ in early onset paranoid psychosis cases when compared to late onset cases (Tonkonogy and Geller 1999) 


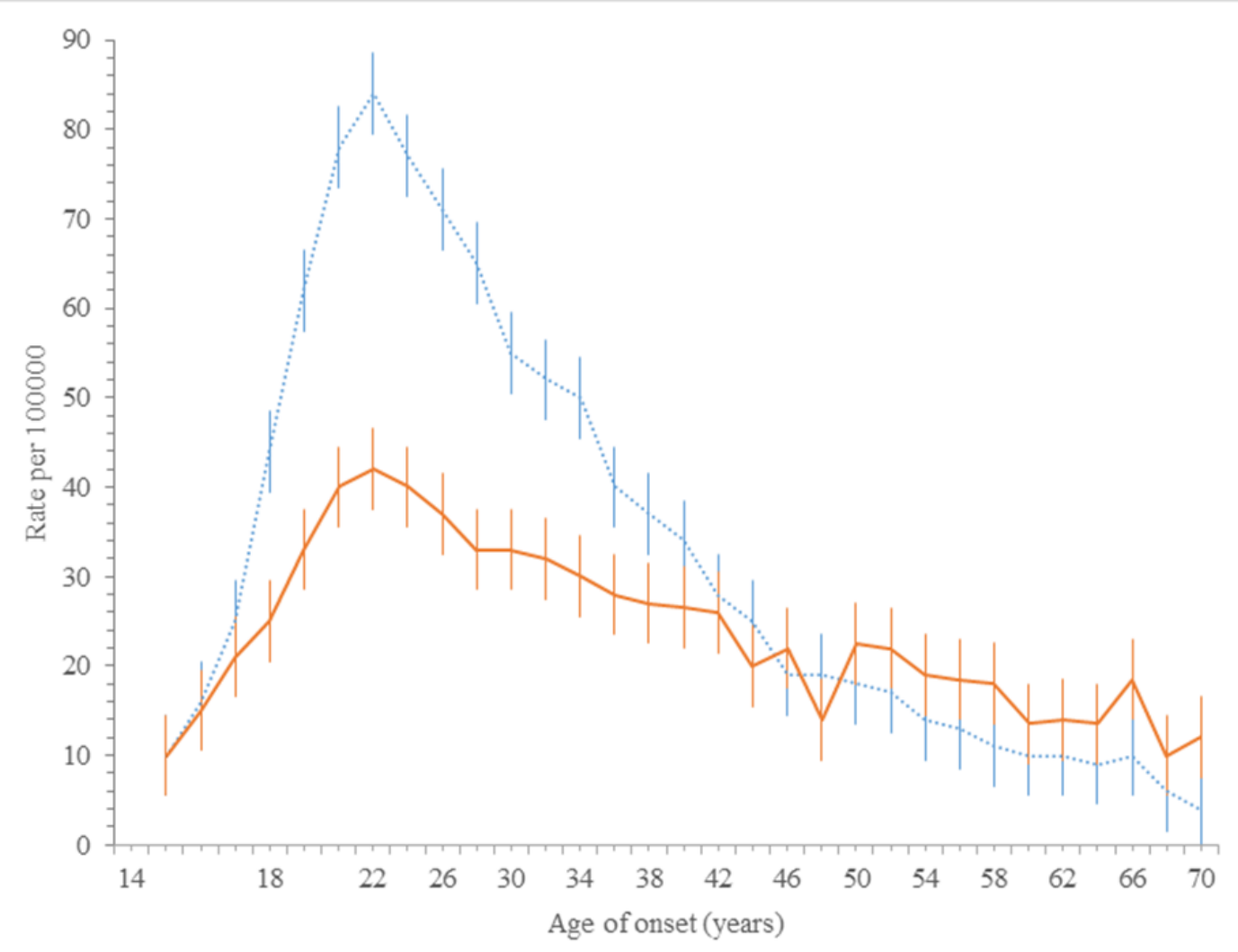

Fig. 4.1 Adjusted incidence rates of schizophrenia by age and gender (baseline is the ICD10 period, 1995-2001). ---, Females; ...., males (reprinted from Thorup et al. (2007) with permission from Cambridge University Press). 
Outcomes

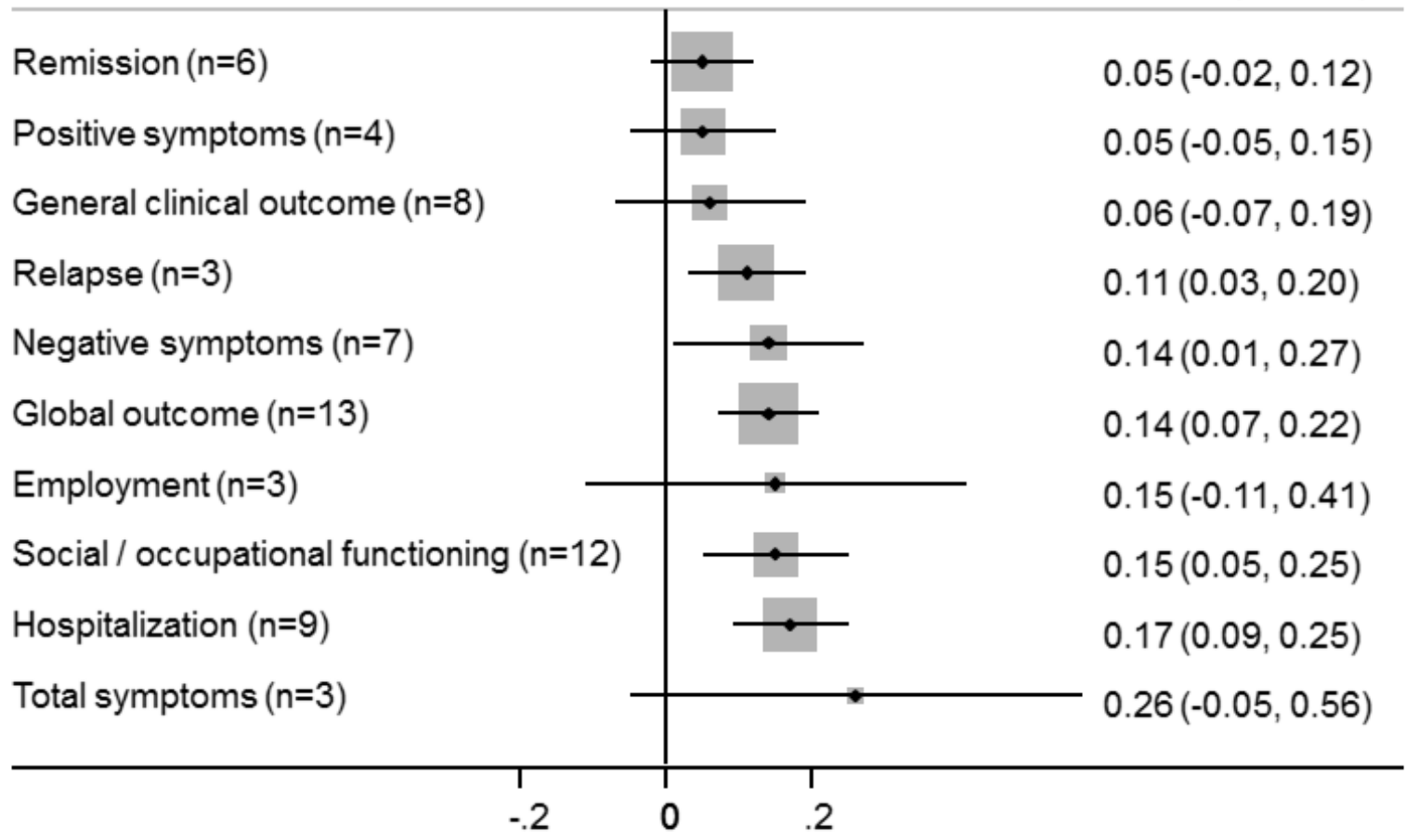

Fig. 4.2 Correlations between age at onset and outcomes (CI, conference interval; $n$, number of studies) (reprinted from Immonen et al. (2017)).

- The peak age of onset (AOO) for schizophrenia is between 20 and 29 years, with males having an earlier AOO.

- Cannabis use, family history of psychosis and poor premorbid adjustment are associated with earlier AOO.

- Earlier onset has been found to be associated with poorer clinical and social outcome and larger deficits in cognition than later onset.

- Later AOO has been linked more suicides.

- Studies on AOO have heterogeneous methods.

Box 4.1 Summary of findings on age of onset in schizophrenia spectrum disorders. 